\title{
ASSOCIATION BETWEEN THE HIGH RISK OCCUPATIONS AND BLADDER CANCER IN IRAN: A CASE-CONTROL STUDY
} JAMSHID KHOUBI $^{1}$, SIAMAK POURABDIAN ${ }^{2}$, IRAJ MOHEBBI
MIN $^{3}$,
MINJVIDI $^{4}$, OMID ZAROORIAN $^{5}$, and OMID GIAHI

${ }^{1}$ Kurdistan University of Medical Sciences, Kurdistan, Iran

Department of Occupational Health, Faculty of Health

${ }^{2}$ Isfahan University of Medical Sciences, Isfahan, Iran

Department of Occupational Health, Faculty of Health

${ }^{3}$ Urmia University of Medical Sciences, Urmia, Iran

Department of Occupational Health, Faculty of Health

${ }^{4}$ Isfahan University of Medical Sciences, Isfahan, Iran

Department of Radiotherapy, Faculty of Medicine

${ }^{5}$ General Practitioner of Raahe Salaamat Occupational Health Clinic, Kurdistan, Iran

${ }^{6}$ Kurdistan University of Medical Sciences, Kurdistan, Iran

Department of Occupational Health, Faculty of Health

\begin{abstract}
Objectives: The objective of this work was to identify the high-risk occupations in Iran and to re-inspect occupations that were related to bladder cancer. Materials and Methods: In the study, 300 patients suffering from bladder cancer and 500 control individuals were interviewed. Demographic information, occupational history, and history of exposure to chemical compounds such as aromatic amines for each participant were collected. ORs and 95\% CIs were calculated using unconditional logistic regression for each occupation. Results: There was a significantly increased risk of bladder cancer among truck and bus drivers $(\mathrm{OR}=11.3)$, skilled agricultural, forestry and fishery workers $(\mathrm{OR}=6.0)$, metal industry workers $(\mathrm{OR}=6.0)$, domestic housekeepers $(\mathrm{OR}=5.9)$, and construction workers $(\mathrm{OR}=3.8)$. Conclusions: The study showed a strong correlation between truck and bus drivers, skilled agricultural, forestry and fishery workers, metal industry workers, domestic housekeepers, as well as construction workers and the increased risk of bladder cancer in these occupations.
\end{abstract}

Keywords:

High risk occupation, Bladder cancer, Iran, Occupational health

Received: March 1, 2012. Accepted: December 10, 2012.

Corresponding author: O. Giahi, Department of Occupational Health, Faculty of Health, Kurdistan University of Medical Sciences, Sanandaj, Kurdistan, Iran (e-mail: omidgi@yahoo.com). 


\section{INTRODUCTION}

Bladder cancer is the third most common type of cancer among men in Iran, and the second in Isfahan [1]. Occupation has been identified as the second most important risk factor for bladder cancer, after smoking. It has been estimated that occupational exposure may account for as much as 20\% of all bladder cancers [2]. Exposure to aromatic amines such as benzidine [3-5], 4-aminobiphenyl (one of the most important ingredients in tobacco that causes cancer) [5], $\beta$-naphthylamine, 4-chloro-o-toluidine in dyestuff manufacture, rubber and other industries, which are the only specific agents, has been undoubtedly associated with bladder cancer [6,7]. Associations of exposure to these agents with bladder cancer have been clearly established, but exposure to other agents such as paints, dyes, metals, industrial cutting fluids, polycyclic aromatic hydrocarbons (PAHs) [5,8] and motor exhaust fumes is also linked to the increased risk of bladder cancer [4,9-14]. Work-related exposure to these potential bladder carcinogens occurs in a number of industries including aromatic amine manufacture, dyestuff manufacturing industries, rubber and cable manufacture, textile and leather works, driving occupations, hairdressing and the coal tar, aluminum, and gas industries [5].

Although more than 40 different occupations have been associated with the elevated risk of bladder cancer, the evidence for most occupations has remained unclear [15]. In this case-control study in Iran, we have investigated various bladder cancer risk factors including occupation, drinking water source, smoking, narcotic consumption, past medical history, as well as life style factors such as drinking tea, coffee, barbecue foods consumption and the history of bladder cancer in the family. We have had two main objectives in this study: to identify the high-risk occupations of bladder cancer that has been increasing in Iran (Isfahan province) every year (Figure 1), and to reinvestigate the high risk occupations that were identified in previous studies.

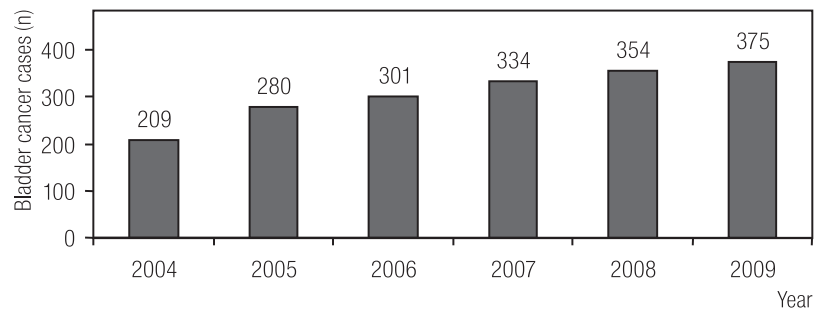

Fig. 1. Distribution and increasing number of cases of bladder cancer in Isfahan province between 2004 and 2009

Working conditions, type and number of occupations, number of employed workers, and young working force were taken into account in this study since these variables may be different in Iran when compared to the developed countries.

\section{MATERIALS AND METHODS}

This case-control study was conducted from 2004 to 2009 and it was based on 300 bladder cancer cases and 500 population controls. The cases included men and women aged 35-93, who had bladder cancer diagnosed during this period, and who were registered in the Cancer Registry Center of Health Department of Isfahan University of Medical Sciences. It should be mentioned that the time interval between the interview and the cancer diagnosis was not long (less than three months); this time gap was devoted to gathering a sufficient number of case sampling. Of 1853 cases in the 6 years, 648 patients (35\%) died due to such parameters as old age and delayed reaction to diagnosis in the end stages (Figure 2), 370 (20\%) refused to participate in the study due to the cultural and social limitations, 257 (14\%) changed residential address, 185 (10\%) did not respond to calls despite several attempts to contact them, and 93 patients who had history of other cancers were excluded from the study. Inclusion criteria comprised valid contact information, ability to speak Farsi and primary diagnosis of bladder cancer. Consent was 


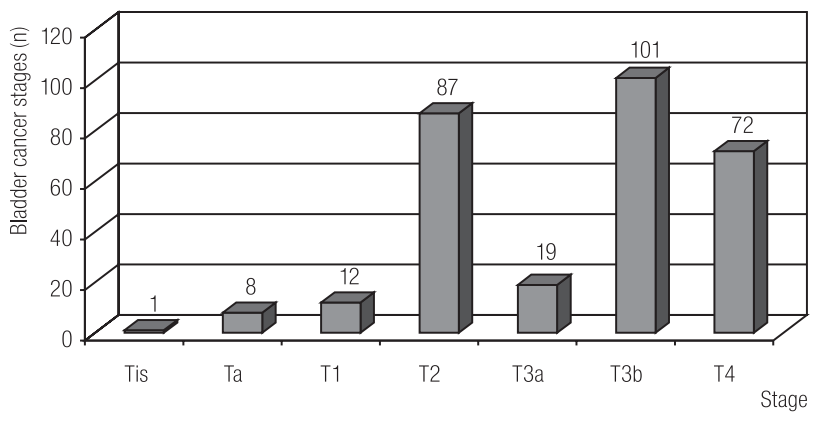

Fig. 2. Bladder cancer stages according to TNM system in Isfahan province between 2004 and 2009

obtained from those who agreed to participate in this study. 300 bladder cancer cases out of 1853 patients registered in the Cancer Registry Center of Health Department of Isfahan University of Medical Sciences agreed to participate in the study. Information was collected by phone or face-to-face interviews.

Population controls were selected from the same region where the cases lived. We chose controls randomly basing on the phone digit number in the area where cases lived. After selecting them we interviewed them and if they had no history of any cancer, we included them in the study, so the cases and controls matched in terms of age, sex and living region. The purpose of the study was explicitly explained so as to obtain the participants' consent. In total, 500 controls participated in the study, providing a response rate of $83.4 \%$. The questionnaire designed to elicit detailed information on demographic factors such as calculated body mass index (BMI), occupational history, background of exposure to chemical materials (particularly aromatic amines), drinking water sources, smoking, narcotic consumption, past medical history, life style factors (drinking tea, coffee, etc.), and family history of bladder cancer. Lifetime occupational history including: every occupation which the case or control performed for at least 6 months, the industry name, job title, number of years spent on performing each profession, number of hours worked per day, chemicals and materials used, and self-reported exposures was collected.
After the data collection, occupational titles were encoded in accordance with the International Standard Classification of Occupation, 2008 (ISCO-08) (International Labor Office 2007) [16] by providing each occupation with a one-, two-, three-, and four-digit ISCO code. One-digit codes indicated major occupational groups, two-digit codes sub-major groups, three-digit codes minor groups, and four-digit codes unit groups. 620 different occupations were classified to 10 major groups in this study. Some occupations were categorized into one group by the occupational health experts due to the relatively small numbers as well as similarity in their potential and exposure.

Thanks to matching compliance of cases and controls by age, sex and living region, these confounders were controlled. Odds ratios, also, were adjusted to other potential confounders including current smoking status, number of cigarettes smoked per day, body mass index, drinking tea, drinking coffee and educational level by the use of logistic model. For analysis of the data and estimation of odds ratio (OR) and corresponding 95\% confidence intervals $(95 \% \mathrm{CI})$, the SPSS 15 software and unconditional logistic regression test for each occupation and industry were used.

\section{RESULTS}

The study results were obtained by interviewing 300 bladder cancer cases, and 500 population controls. Cases included 269 males (89.7\%), 31 females (10.3\%) whereas the controls included 464 males $(92.8 \%), 36$ females $(7.2 \%)$, with a mean age of $68.9(\mathrm{SD}=10.9)$ years among the cases and $67.4(\mathrm{SD}=10.1)$ among the controls. Average body mass index (BMI) was 23.6 $(\mathrm{SD}=4.2)$ and 25.6 ( $\mathrm{SD}=3.7)$ in cases and controls, respectively (Table 1). The staging system most often used for bladder cancer is that of the American Joint Committee on Cancer (AJCC). This is also called the Tumor, 
Table 1. Characteristics of the study participants

\begin{tabular}{|c|c|c|c|c|}
\hline \multirow{2}{*}{ Variable } & \multicolumn{2}{|c|}{ Bladder cancer cases } & \multicolumn{2}{|c|}{ Population controls } \\
\hline & $\mathrm{n}$ & $\%$ & $\mathrm{n}$ & $\%$ \\
\hline Total & 300 & 100.00 & 500 & 100.00 \\
\hline \multicolumn{5}{|l|}{ Gender } \\
\hline female & 31 & 10.30 & 36 & 7.20 \\
\hline male & 269 & 89.70 & 464 & 92.80 \\
\hline \multicolumn{5}{|l|}{ Age during the interview (years) } \\
\hline $30-40$ & 4 & 1.30 & 5 & 1.00 \\
\hline $41-50$ & 18 & 6.00 & 38 & 7.60 \\
\hline $51-60$ & 50 & 16.70 & 81 & 16.20 \\
\hline $61-70$ & 86 & 28.70 & 163 & 32.60 \\
\hline $71-80$ & 109 & 36.30 & 188 & 37.60 \\
\hline$\geq 81$ & 33 & 11.00 & 25 & 5.00 \\
\hline \multicolumn{5}{|l|}{ Smoking status } \\
\hline years smoked (mean) & 21.5 & - & 20.2 & - \\
\hline number cigarettes per day (mean (SD)) & $13.0(13.4)$ & - & $9(10.5)$ & - \\
\hline never & 111 & 37.00 & 164 & 33.00 \\
\hline former & 68 & 22.60 & 119 & 23.80 \\
\hline current & 121 & 40.40 & 217 & 43.40 \\
\hline \multicolumn{5}{|l|}{ Education level } \\
\hline level 1 (illiterate) & 139 & 46.30 & 139 & 27.80 \\
\hline level 2 (primary) & 44 & 14.70 & 99 & 19.80 \\
\hline level 3 (middle school) & 64 & 21.30 & 145 & 29.00 \\
\hline level 4 (high school) & 41 & 13.70 & 63 & 12.60 \\
\hline level 5 (university) & 12 & 4.00 & 54 & 10.80 \\
\hline
\end{tabular}

SD - standard deviation.

Node, Metastasis (TNM) system. Using this system in the staging of bladder cancer, we observed: Tis $(0.4 \%)$, Ta (2.7\%), T1 (4\%), T2 (29\%), T3a (6.3\%), T3b (33.6\%) and $\mathrm{T} 4(24 \%)$.

The results of our study indicated that there was no significant difference in the number of years of smoking in two groups $(p=0.7)$. However, the difference in the number of daily cigarette consumption was significant $(\mathrm{p}<0.001)$ the effect of which was controlled in a multivariate model (unconditional logistic regression) $(\mathrm{p}<0.001)$.
In the study, in total, 87 occupations were identified among the cases and controls. These occupations were categorized into 22 groups according to the exposure agents and nature of the job. After grouping job titles in accordance with the International Standard Classification of Occupations (ISCO-08), correlation between a significantly increased risk of bladder cancer and occupation among heavy truck and bus drivers ( $\mathrm{OR}=11.3,95 \%$ CI: 1.32-92.5) skilled agricultural, forestry and fishery workers $(\mathrm{OR}=6.0,95 \% \mathrm{CI}: 2.32-15.72)$, sheet and structural metal 
Table 2. Odds ratios and 95\% confidence intervals for bladder cancer according to occupations classified by ISCO-08 codes

\begin{tabular}{|c|c|c|c|c|c|}
\hline ISCO-08 & Occupation $^{\mathrm{a}}$ & $\begin{array}{c}\text { Bladders } \\
\text { cancer cases } \\
(\mathrm{n})^{\mathrm{b}}\end{array}$ & $\begin{array}{l}\text { Controls } \\
\text { (n) }\end{array}$ & $\mathrm{OR}^{\mathrm{c}}$ & $95 \% \mathrm{CI}$ \\
\hline 22 & Health professionals & 6 & 20 & 0.4 & $0.04-4.80$ \\
\hline 3134 & Petroleum and natural gas refining plant operators & 6 & 24 & 0.4 & $0.18-1.50$ \\
\hline $40-44$ & Clerks & 11 & 43 & 0.2 & $0.11-2.49$ \\
\hline 5152 & Domestic housekeepers & 31 & 10 & 5.9 & $2.61-11.62$ \\
\hline 52 & Sales workers & 15 & 48 & 2.8 & $0.81-2.01$ \\
\hline 522 & Shop assistants & 14 & 45 & 3.4 & $0.91-7.21$ \\
\hline 60 & Skilled agricultural, forestry and fishery workers & 75 & 31 & 6.0 & $2.32-15.72$ \\
\hline 612 & Animal producers & 6 & 4 & 2.5 & $0.70-9.04$ \\
\hline 71 & Building and related trades workers, excluding electricians & 29 & 14 & 3.8 & $1.33-3.21$ \\
\hline 7115 & Carpenters and joiners & 7 & 4 & 2.9 & $0.77-12.13$ \\
\hline 7131 & Painters and related workers & 14 & 17 & 1.8 & $0.20-4.21$ \\
\hline 721 & Sheet and structural metal workers, moulders and welders & 28 & 8 & 6.0 & $2.84-14.08$ \\
\hline 751 & Food processing and related trades workers & 7 & 36 & 1.0 & $0.22-3.52$ \\
\hline 832 & Car, van and motorcycle drivers & 6 & 12 & 0.6 & $0.07-5.60$ \\
\hline 833 & Heavy truck and bus drivers & 19 & 3 & 11.3 & $1.32-92.50$ \\
\hline 931 & Mining and construction laborers & 18 & 33 & 1.2 & $0.30-4.41$ \\
\hline
\end{tabular}

${ }^{a}$ Only jobs done for more than 6 months are recorded.

${ }^{\mathrm{b}}$ Number of people employed in each ISCO-08 code.

${ }^{c}$ Odds ratios adjusted for age, sex, living region, current smoking status, number of cigarettes smoked per day, body mass index, drinking tea, drinking coffee and educational level.

workers, molders and welders (OR $=6.0,95 \% \mathrm{CI}: 2.84$ 14.08), domestic housekeepers ( $\mathrm{OR}=5.9,95 \%$ CI: 2.61 11.62), and construction and related trades workers, excluding electricians (OR $=3.8,95 \%$ CI: $1.33-3.21)$ was indicated. No other occupational group demonstrated a significant increase in OR statistically, while several occupational groups exhibited non-significantly increased ORs $(\mathrm{OR}>1.0)$. These occupations included carpenters and joiners (OR $=2.96,95 \% \mathrm{CI}: 0.77-12.13)$, sales workers $(\mathrm{OR}=2.8,95 \% \mathrm{CI}: 0.81-2.01)$, painters and related workers $(\mathrm{OR}=1.8,95 \% \mathrm{CI}: 0.20-4.21)$, food processing and related trades workers $(\mathrm{OR}=1.0,95 \% \mathrm{CI}$ : 0.22-3.52). Table 2 presents ORs adjusted to all occupations indicated by two-, three-, and four-digit ISCO codes.

\section{DISCUSSION AND CONCLUSIONS}

In this case-control study, 300 bladder cancer cases and 500 population controls were interviewed. After adjusting the two groups in terms of age sex and living region, it became clear that heavy truck and bus drivers (ISCO 833) were more at risk of bladder cancer than the other participants (OR $=11.3,95 \%$ CI: $1.30-92.05)$. This finding was compatible with the findings of similar studies carried out in Spain and Western Europe [6,10,12,23]. It may be due to exposure to many hazards such as diesel exhaust fumes [9-19], smoke, oil and oil compounds. Diesel exhaust fumes contain many aromatic nitro compounds which are capable of creating some intermediaries such as aromatic amines in the body [19-20]. These fumes 
also contain polycyclic aromatic hydrocarbons [21] which can increase the risk of bladder cancer among the forementioned workers [22].

The second group which is threatened by bladder cancer consisted of the skilled agricultural, forestry, fishery workers and farmers. In the studies carried out in recent decades on the association between agricultural employment and the high risk of bladder cancer, the researchers have seldom found a significant statistical association.

For example; the study conducted in 2007 by CM Samanic and his colleagues in Spain, found no association between these variables (OR $=0.8,95 \%$ CI: 0.06-1.0) [24]. Similar studies found an association between this occupation and the reduced risk of bladder cancer as a result of low prevalence of smoking cigarette, proper diet, and high physical activity. This study showed a significant association between agricultural employment and the increased bladder cancer risk among men (ISCO 60, $\mathrm{OR}=6.0,95 \% \mathrm{CI}: 2.32-15.72)$. This relationship was not significant in case of women $(\mathrm{OR}<1.0)$.

This significance was probably caused by the past history of agriculture in the province and country, uncontrolled use of pesticides including insecticides, herbicides and carbamate poisons that are chemical compounds containing Nitrogen (amining agent) in their structures. Exposure to aromatic amines such as benzidine, 4-amino biphenyl, $\beta$-naphthylamine, and 4-chloro-o-tolouidine was also likely to increase the risk of bladder cancer. These chemicals are used in industries such as paint manufactures, rubber and some other industries [9]. The studies showed an extraordinary carcinogenic potential of $\beta$-naphthylamine in humans with a 200-fold elevated bladder cancer risk [17]. Polycyclic aromatic hydrocarbons (PAHs) [5,8-9] and motor diesel exhaust [9-15] were also related to the elevated risk of bladder cancer.

The studies carried out between 1990 and 1995 confirmed the influence of these poisons on the increasing number of deaths due to bladder cancer. Paraquat, with the chemical formula $\mathrm{C} 2 \mathrm{H} 14 \mathrm{~N} 2$ is one of the most important herbicides that increase the risk of bladder cancer [25,26]. Challier and Viel (1995) found that the mortality rate resulting from bladder cancer among the grape farmers exposed to pesticides in France was not higher than among the rest of population. However, the farmers tended to smoke fewer cigarettes than ordinary people and thus they should have lower mortality rate. And so, this lack of difference was linked to the effect of the pesticides [27].

Another important research conducted by Kabat (1986) on non-smokers in the U.S indicated that the odds ratio was significantly increased among non-smoking farmers, which strengthened the concept of bladder cancer inducing effect of pesticides $(\mathrm{OR}=9.7, \mathrm{p}<0.05)$ [28].

Koutros et al. (2009) in the U.S evaluated the effect of pesticides, herbicides, which contain aromatic amine (Imazethapyr), and the risk of bladder cancer. In this study a significant trend was observed between the risk of bladder cancer and the increased exposure time $(R R=137 \%$, $\left.\mathrm{p}_{\text {trend }}=0.01\right)[7]$.

Furthermore, in our study, the risk of bladder cancer was increased 6 times among sheet and structural metal workers, molders and welders in Isfahan compared to the control group (ISCO 721, OR = 6.0, 95\% CI: 2.84-14.08). This was probably due to the exposure to cutting oils $(13,28)$, which might contain aromatic amines as additives and also N-nitrosamines [22]. This finding is similar to the findings of Kogevinas et al. (2003) [6]. It is also compatible with the results of the study by Hours et al. (1994) which showed that the risk of bladder cancer among the cases was 2.5 times greater than among the control group (OR $=2.5,95 \%$ CI: 1.2-1.4) [29].

In another study conducted by Colt et al. (2004), the risk of bladder cancer among male operators in metal industries, who were involved in welding and molding, was 16.6 times higher than among the control group (OR = 16.6). The risk was caused by the exposure of participants to oil 
compounds (carbohydrate) such as linseed oil, fuel oil or furnace oil and coal tar pitch during a twenty-year period of their seniority [30].

In this study, a significant association was observed between domestic housekeepers and the increasing risk of bladder cancer among women $(\mathrm{OR}=5.9,95 \% \mathrm{CI}$ : 2.6111.62). However the reason is not obvious. It might be a result of the participant's exposure to washing agents and detergents, and the smoke from frying food oil. This finding is similar to the result of the study by Reulen et al. (2007) in Belgium, in which housekeepers and cleaners were reported as more likely threatened by bladder cancer (OR $=2.7,95 \%$ CI: 1.1-6.6) [31].

Studies carried out by Silverman (1989) [30], Porrue et al. (1996), showed that construction occupations such as stone masoning, insulation, etc. were considered as high bladder cancer risk occupations (OR > 1.0). In addition, Risch et al. (1988) found 3.11 times increased risk of bladder cancer among road workers who were exposed to asphalt and tar [33].

In this study a significant association between construction and related trade workers, excluding electricians, and the increased bladder cancer risk was found, the causes of which is not perfectly clear. However, exposure to asphalt and other hydrocarbon compounds may contribute to such a risk. Cases in this study were at risk 3.8 times greater than the controls (ISCO 71, OR $=3.8,95 \%$ CI: $1.33-3.21$ ).

Hairdressing was identified as one of the highest risk occupations of bladder cancer because of the exposure to dye $[9,34,35]$. In this study no significant association was identified between them. Painters might be threatened by the risk of bladder cancer because of their frequent exposure to paint components and polycyclic aromatic hydrocarbons [9]. Some studies, however, found no significant association between them [12,36]. This probably depends on the kind of material, painting style, and the extent of individual contact which differs from one country to another. For example, painters who paint the building walls with $\mathrm{TiO}_{2}$ (titanium dioxide) base paint, white color, or other mineral paints(colored) showed no increase in bladder cancer risk, whereas painters who were frequently exposed to aniline base paints from the 1940 s to 1950 s, were at greater risk of bladder cancer [21].

In this study, there was no significant association between painting and bladder cancer (ISCO 7131, $\mathrm{OR}=1.8,95 \%$ CI: 0.20-4.21). Moreover, no significant association was observed between the occupations in textile industries, rubber, paint, print, leather and shoes, and the increased risk of bladder cancer $(\mathrm{OR}<1.0)$.

The result of this study demonstrated probable relationship of aromatic amines, an important group of chemicals contributing to bladder cancer, with some high risk occupations in Isfahan. In the investigation, the occupations such as heavy truck and bus drivers, skilled agricultural, forestry and fishery workers, sheet and structural metal workers, molders and welders, domestic housekeepers, as well as construction and related trades workers, excluding electricians, were identified as the highest risk occupations leading to bladder cancer (OR > 1.0).

Generally, it seems that the status of high risk occupations in Isfahan was similar to the one in other countries. Only agriculture was rarely considered as a high risk occupation in other countries. This difference is probably caused by the long past history of agriculture in this region, uncontrolled use of poisons, ignoring the extent of exposure, and inappropriate use of protective equipment.

\section{ACKNOWLEDGEMENTS}

This project was founded by the Isfahan University of Medical Sciences. We also thank Dr. Simin Hemmati for his assistance in data collection. 


\section{REFERENCES}

1. Center for Disease Control \& Prevention of Non-communicable Deputy Cancer Office. Iranian Annual of National Cancer Registration Report [2006-2007]. Iran: Center; 2010. p. 56-155.

2. Vineis P, Simonato L. Proportion of lung and bladder cancers in males resulting from occupation: A systematic approach. Arch Environ Health 1991;46:6-15.

3. International Agency for Research on Cancer. Overall evaluations of carcinogenicity: An updating of selected IARC monographs. Lyon: IARC; 1987.

4. Kogevinas M, Trichopoulos D. Urinary bladder cancer. In: Adami HO, Hunter D, Trichopoulos D, editors. Textbook of cancer epidemiology. New York: Oxford University Press; 2002. p. 446-66.

5. International Agency for Research on Cancer. Occupational exposures of hairdressers and barbers and personal use of hair colorants; some hair dyes, cosmetic colorants, industrial dyestuffs and aromatic amines. IARC monographs on the evaluation of carcinogenic risks to humans. Lyon: IARC; 1994.

6. Kogevinas M, Mannetje A, Cordier S, Ranft U, GonzálezCA, Vineis $\mathrm{P}$, et al. Occupation and bladder cancer among men in Western Europe. Cancer Causes Control 2003;14:907-14.

7. Koutros S, Lynch CF, Ma X, Lee WJ, Hoppin JA, Christensen $\mathrm{CH}$, et al. Heterocyclic aromatic amine pesticide use and human cancer risk: results from the U.S. Agricultural Health Study. Int J Cancer 2009;124:1206-12.

8. Olfert SM, Felknor SA, Delclos GL. An updated review of the literature: risk factors for bladder cancer with focus on occupational exposures. South Med J 2006;99:1256-63.

9. Zeegers MP, Swaen GM, Kant I, Goldbohm RA, van den Brandt PA. Occupational risk factors for male bladder cancer: results from a population-based case cohort study in the Netherlands. Occup Environ Med 2001;58:590-6.

10. Silverman DT, Hoover RN, Albert S, Graff KM. Occupation and cancer of the lower urinary tract in Detroit. J Natl Cancer Inst 1983;70:237-45.
11. Baxter PJ, McDowall ME. Occupation and cancer in London: An investigation into nasal and bladder cancer using the Cancer Atlas. Br J Ind Med 1986;43:44-9.

12. Claude J, Kunze E, Frentzel-Beyme R. Occupation andrisk of cancer of the lower urinary tract among men: A case-control study. Int J Cancer 1988;41:271-9.

13. Schoenberg JB, Stemhagen A, Mogielnicki AP, Altman R, Abe T, Mason TJ. Case-control study of bladder cancer in New Jersey: occupational exposures in white males. J Natl Cancer Inst 1984;72:973-81.

14. Smith AH, Pearce NE, Callas PW. Cancer case-control studies with other cancers as controls. Int J Epidemiol 1988;17: 298-306.

15. Silverman DT, Hoover RN, Mason TJ, Swanson GM. Motor exhaust-related occupations and bladder cancer. Cancer Res 1986;46:2113-6.

16. International Labour Organization. International Standard Classification of Occupations 2008 (ISCO-08). New York: ILO; 2007.

17. Case RAM, Hosker ME. Tumors of the urinary bladder as an occupational disease in the rubber industry in England and Wales. Br J Prev Soc Med 1971;8:39-50.

18. Porru S, Aulenti V, Donato F, Boffetta P, Fazioli R, Cosciani Cunico S, et al. Bladder cancer and occupation: A casecontrol study in northern Italy. Occup Environ Med 1996;53: 6-10.

19. Wynder EL, Dieck GS, Hall NEL, Lahti H. A case-control study of diesel exhausts exposure and bladder cancer. Environ Res 1985;37:475-81.

20. Hoak SK, Hoover R. Truck driving and bladder cancer mortality in rural New England. J Natl Cancer Inst 1985;71:774-80.

21. Golka K, Wiese A, Assennato G, Bolt HM. Occupational exposure and urological cancer. World J Urol 2004;21:382-91.

22. Dryson E, Walls C, McLean D, Pearce N. Occupational bladder cancer in New Zealand: A 1 year review of cases notified to the New Zealand Cancer Registry. Int Med J 2005;35:343-7.

23. Gonzalez CA, Lopez-Abente G, Errezola M, Escolar A, Riboli E, Izarzugaza I, et al. Occupation and bladder cancer 
in Spain: A multi-venter case-control study. Int J Epidemiol 1989;18:569-77.

24. Samanic CM, Kogevinas M, Silverman DT, Tardón A, Serra C, Malats N, et al. Occupation and bladder cancer in a hospital-based case-control study in Spain. Occup Environ Med 2008;65:347-53.

25. Forastiere F, Quercia A, Miceli M, Settimi L, Terenzoni B, Rapiti E, et al. Cancer among farmers in central Italy. Scand J Work Environ Health 1993;19:382-9.

26. Fincham SM, Hanson J, Berkel J. Patterns and risks of cancer in farmers in Alberta, Canada. Cancer 1992;69:1276-85

27. Viel JF, Challier B. Bladder cancer among French farmers: Does exposure to pesticides in vineyards play a part? Occup Environ Med 1995;52:587-92.

28. Kabat GC, Dieck GS, Wynder EI. Bladder cancer in nonsmokers. Cancer 1986;57:362-7.

29. Hours M, Dananche B, Fevotte J, Bergeret A, Ayzac L, Cardis E, et al. Bladder cancer and occupational exposures. Scand J Work Environ Health 1994;20:322-30.

30. Colt JS, Baris D, Stewart P, Schned AR, Heaney JA, Mott LA, et al. Occupation and bladder cancer risk in a population-based case-control study in New Hampshire. Cancer Causes Control 2004;15:759-69.
31. Reulen RC, Kellen E, Buntinx F, Zeegers MP. Bladder cancer and occupation: A report from the Belgian case-control study on bladder cancer risk. Am J Ind Med 2007;50:449-54.

32. Silverman DT, Levin LI, Hoover RN, Hartge P. Occupational risks of bladder cancer in the United States: I. White men. J Natl Cancer Inst 1989;81:1472-80.

33. Risch HA, Burch JD, Miller AB, Hill GB, Steele R, Howe GR. Occupational factors and the incidence of cancer of the bladder in Canada. Br J Ind Med 1988;45:361-7.

34. Silverman DT, Devesa SS, Moore LE, Rothman N. Bladder cancer. In: Schottenfeld D, Fraumeni JF Jr, editors. Cancer epidemiology and prevention. New York: Oxford University Press; 2006. p. 1101-27.

35. Dryson E, Mannetje A, Walls C, McLean D, McKenzie F, Maule M, et al. Case-control study of high risk occupations for bladder cancer in New Zealand. Int J Cancer 2008;122: $1340-6$.

36. International Agency for Research on Cancer. IARC monographs on the evaluation of the carcinogenic risk of chemicals to humans: some organic solvents, resin monomers and related compounds, pigments, and occupational exposures in paint manufacture and painting. Lyon: World Health Organization; 1989.

This work is available in Open Access model and licensed under a Creative Commons Attribution-NonCommercial 3.0 Poland License - http://creativecommons.org/ licenses/by-nc/3.0/pl/deed.en. 